\title{
A CIRCULARIDADE ENTRE SISTEMAS SEMIÓTICOS COMO APOIO AO(S) LETRAMENTO(S) NA ESCOLA INCLUSIVA
}

Raquel Salcedo Gomes*

CÁtia De Azevedo Fronza**

\section{RESUMO}

Partindo dos conceitos de multiplicidade e circularidade da teoria sistêmica, analisou-se uma produção textual resultante de atividade aplicada em uma Sala de Recursos e refletiu-se sobre o desenvolvimento linguístico de um educando em situação de inclusão. A opção por esses conceitos, no processo de produção textual do aluno, e as concepções de inclusão, letramento(s) e sistemas semióticos fundamentam-se no conceito de linguagem como ação, pós-virada linguística. Os movimentos circulares desempenhados pelo aluno em sua atividade de produção textual reiteram a potencialidade da visão sistêmica sobre as linguagens e os letramentos como sistemas abertos em permanente mudança.

Palavras-chave: sistemas semióticos, letramentos, escola inclusiva, sala de recursos multifuncional.

\section{INTRODUÇÃO}

Com base em dois conceitos da perspectiva teórica sistêmica multiplicidade e circularidade -, o propósito deste texto é refletir sobre os efeitos de uma atividade de produção textual, tendo como foco o desenvolvimento linguístico de um educando em situação de inclusão. Para tanto, foi realizada a análise linguística de uma produção textual resultante de atividade aplicada na Sala de Recursos em contexto de Atendimento Educacional Especializado (AEE).

* Professora de Língua Inglesa da Rede Municipal de Educação da cidade de Novo Hamburgo e Doutoranda na Universidade do Vale do Rio dos Sinos.

E-mail: salcedogomes@gmail.com

** Professora do Curso de Letras, do Curso de Pedagogia e do Programa de Pós-Graduação em Linguística Aplicada da Universidade do Vale do Rio dos Sinos.

E-mail: catiaaf@unisinos.br 
Com a profusão de imagens que abundam no cotidiano da sociedade, torna-se necessário desenvolver pesquisas sobre o apelo dos sistemas visuais de comunicação que se hibridizam e influenciam nos modos como os seres humanos desenvolvem sua cognição. Há demanda por investigar atividades efetivamente implementadas em contextos de educação inclusiva, discutindo suas consequências para a aprendizagem dos alunos envolvidos e buscando compreender o quanto elas personificam o conceito de inclusão proposto nos textos normativos, jurídicos e acadêmicos sobre o tema.

\section{Percursos metodológicos na sala de Recursos multifuncional}

A pesquisa aqui relatada caracteriza-se como uma investigação qualitativa, levada a campo durante o período de quatro meses, com elementos de pesquisa-ação. Foram realizadas duas entrevistas semiestruturadas com a psicopedagoga da Sala de Recursos Multifuncional, além da observação participante de um conselho de classe, uma reunião pedagógica na escola do aluno pesquisado e de aulas regulares por ele frequentadas. Também houve a análise de documentos escolares e médicos do estudante e das várias versões de suas produções textuais elaboradas com a psicopedagoga em sessões de Atendimento Educacional Especializado.

A atividade de produção textual sob análise ocorreu na Sala de Recursos Multifuncional de uma escola da Rede Municipal de Ensino de uma cidade no Vale dos Sinos, Rio Grande do Sul. A escola oferece Ensino Fundamental completo, atende cerca de 350 alunos e conta com aproximadamente 40 colaboradores, entre professores e demais funcionários.

A Sala de Recursos Multifuncional dessa escola atende alunos com necessidades especiais de mais três instituições educacionais da região. $\mathrm{O}$ aluno que desenvolveu a atividade estuda em outra escola, menor, situada em localidade afastada. A prefeitura fornece transporte para que ele frequente a Sala de Recursos semanalmente.

O menino, doravante chamado Francisco, cursa o $6^{\circ}$ ano do Ensino Fundamental. Sua turma é relativamente pequena, com 18 educandos, mas, de acordo com relato das professoras em conselho de classe, é uma turma em que muitos alunos demonstram dificuldades e pouco 
interesse pela aprendizagem. Em seu Registro de Atividades, consta que Francisco apresenta diagnóstico de paralisia cerebral com prejuízos motores que atinge suas duas pernas, o braço e a mão esquerda.

Também consta que Francisco usa óculos e que suas dificuldades de aprendizagem se relacionam ao processo de aquisição de leitura e escrita. De acordo com os documentos consultados, o aluno lê devagar, necessitando de mais tempo para a resolução de situações-problema e para a identificação de dados textuais. Com a mão direita, consegue desenhar e fazer o traçado das letras, mas apresenta limitações quanto à coordenação motora fina.

Nos registros de frequência do Serviço de Apoio Especializado, Francisco é descrito como um aluno participativo, disposto a ajudar, sentindo-se capaz de realizar as mesmas atividades que os demais colegas e, em virtude disso, colocando-se em risco em algumas situações.

É preciso notar que os documentos sobre Francisco, em posse da professora psicopedagoga, são somíticos e de períodos espaçados. Em uma das duas entrevistas realizadas a fim de coletar registros e informações, ela explicou que esses documentos não the são automaticamente remetidos. Todos os materiais que queira armazenar para fazer um acompanhamento contínuo dos alunos são acessíveis somente mediante a solicitação a outros órgãos da prefeitura e à família, que nem sempre lhe disponibilizam.

A maioria dos registros sobre Francisco, exceto aqueles produzidos pela psicopedagoga e por suas professoras nos pareceres pedagógicos, trata de suas condições de saúde e limitações. Pouco se fala sobre suas características pessoais, sociais e a respeito de sua potencialidade. É no último Registro de Atividades, produzido pela psicopedagoga e datado de maio de 2011, que se podem observar maiores relatos tratando de suas especificidades de aprendizagem e explicitando o plano de estudos delineado, as atividades previstas e os objetivos subjacentes ao atendimento na Sala de Recursos.

A fim de ilustrar o tipo de descrição produzido pela psicopedagoga, eis um trecho deste último Registro de Atividades:

Tem boa oralidade e memória auditiva. Consegue relatar fatos de um modo coerente, organizando suas ideias. Apesar da sua leitura ainda ser pausada, tem mostrado uma maior disponibilidade para 
tal atividade e principalmente para resolver situações práticas (ler as etiquetas dos potes de materiais). Ao escrever apresenta dúvidas quanto à segmentação das palavras. Quando questionado percebe suas trocas e omissões de letras. Estas trocas relacionam-se à consciência fonológica e à transcrição fonética. Em um jogo no computador mostrou mais facilidade para montar as palavras onde as sílabas já estavam dispostas. (Registro de AtividAdes de Francisco, maio, 2011, p. 1)

A psicopedagoga explicita as habilidades de Francisco relacionadas ao que ele realiza em letramento e deixa implícitas aquelas não plenamente desenvolvidas. Afirma que Francisco adora jogos e desafios. No computador, consegue manusear o mouse, mas, ao digitar, não apresenta agilidade para encontrar as letras nas teclas. Demonstra desenvoltura em tarefas que envolvem oralidade e sociabilidade, consegue relatar eventos passados, presentes e futuros e descrever pessoas e objetos, além de estabelecer relações e expressar necessidades, desejos e interesses.

De acordo com o documento, o aluno tem apresentado dificuldades para copiar do quadro, ler e produzir uma escrita espontânea. Segundo relato da professora de Português, no início do ano letivo, Francisco lhe pedia que separasse as palavras escritas no quadro-negro com um hífen, pois não conseguia distingui-las claramente. Este fato foi observado também por outras professoras.

Visto que a maioria das dificuldades de Francisco relaciona-se com o texto escrito, a psicopedagoga orientou as professoras a lhe prepararem atividades escritas sempre com fonte arial, em negrito, de tamanho 16, a fim de ajudá-lo a enfrentar os obstáculos da baixa visão.

A psicopedagoga delineou um plano de estudos visando a estimular o desenvolvimento da compreensão, interpretação e leitura de Francisco. Ela traçou seu plano com as habilidades nas quais pretendia investir durante as sessões de atendimento individualizado na Sala de Recursos Multifuncional durante os três meses seguintes: junho, julho e agosto.

Os objetivos de aprendizagem abarcados neste plano eram: 1) ler textos com maior fluência; 2) escrever diferentes tipos de textos; 3) mostrar seus conhecimentos de uma forma autônoma, acreditando nas suas hipóteses e no seu potencial; 4) sistematizar os conhecimentos 
trabalhados em sala de aula, na direção de uma maior formalização; 5) desenvolver o uso de estratégias para a resolução de situações-problema; 6) utilizar conhecimentos e habilidades construídos em situações distintas; 7) desenvolver maior autonomia quanto à circulação no espaço escolar; 8) usar recursos que lhe possibilitem aprender com maior independência (REgistro DE AtIVIDAdes, maio, 2011, p. 3).

A partir destes objetivos, o plano trazia uma lista de atividades, dentre as quais constava a produção textual sobre a qual nos debruçamos neste artigo. Segundo o documento, essa produção prevê "a utilização do computador como uma ferramenta que amplie suas possibilidades de escrita" (p. 3). Procederemos ao detalhamento da atividade realizada na penúltima seção deste trabalho, na qual também analisaremos a produção textual resultante da atividade.

A descrição do contexto em foco é relevante a fim de detalhar as especificidades em que o atendimento na Sala de Recursos aconteceu. Outra observação pertinente, que fazemos a partir de leituras realizadas sobre a temática da inclusão, diz respeito ao papel polêmico que a Sala de Recursos e outros elementos da educação especial desempenham na educação inclusiva (CARVALHO, 2000).

Advoga-se que a inclusão deve ocorrer na sala de aula regular e que o professor regente do aluno deve estar habilitado a proporcionar-lhe situações de contínuo aprendizado no cotidiano da escola, ou seja, a inclusão é responsabilidade de todos os envolvidos no processo educacional, não apenas dos peritos em educação especial. Nesse sentido, o atendimento na Sala de Recursos pode ser visto como um entrave à "verdadeira" inclusão, que deve acontecer em todas as dependências da escola.

Defendemos, a esse respeito, que a Sala de Recursos Multifuncional opera como um suporte ao aluno e ao professor em contexto de inclusão, não sendo $a$ responsável pela inclusão desse aluno na escola, mas atuando como uma agente colaboradora da inclusão. As Salas de Recursos estão previstas em lei, tendo sido projetadas exatamente para esta finalidade, conforme as Diretrizes nacionais para a educação especial na educação básica:

Salas de recursos: serviço de natureza pedagógica, conduzido por professor especializado, que suplementa (no caso dos superdotados) 
e complementa (para os demais alunos) o atendimento educacional realizado em classes comuns da rede regular de ensino. Esse serviço realiza-se em escolas, em local dotado de equipamentos e recursos pedagógicos adequados às necessidades educacionais especiais dos alunos, podendo estender-se a alunos de escolas próximas, nas quais ainda não exista esse atendimento. Pode ser realizado individualmente ou em pequenos grupos, para alunos que apresentem necessidades educacionais especiais semelhantes, em horário diferente daquele em que frequentam a classe comum. (BRAsIL, 2001, p. 50)

Desse modo, o atendimento educacional especializado realizado na Sala de Recursos complementa o processo de aprendizagem do aluno participante desta pesquisa, orientando-o a fim de potencializar seu aprendizado na sala de aula. É a partir desta perspectiva que concebemos o contexto escolar e a Sala de Recursos como lugares da multiplicidade, percebendo os sujeitos também como representantes dessa multiplicidade, pois, lá, alunos com diferentes necessidades educativas especiais recebem atendimentos que buscam alcançá-los nas dificuldades não contempladas na sala de aula, existentes em razão das limitações físicas e/ou psíquicas.

Em 1985, Ítalo Calvino proferiu uma série de palestras com propostas para o novo milênio. Elas tornaram-se livro e a última delas intitula-se "Multiplicidade". O autor diz que, cada vez mais, o mundo da cultura está se complexificando, tornando-se múltiplo, mergulhado em um sem-número de sistemas e de linguagens que se sobrepõem e entrecruzam (CALVINO, 1990).

Similarmente, fala-se no campo pedagógico sobre as múltiplas inteligências, proposição elaborada por Gardner (1995). Ainda, no campo da epistemologia da ciência em geral, circula a teoria dos sistemas complexos, que prevê que os vários sistemas naturais e culturais em que o ser humano se insere estão interligados e funcionam, ao mesmo tempo, de modo autônomo. Sobre isso, Capra (1996, p. 41) afirma que "embora possamos discernir partes individuais em qualquer sistema, essas partes não são isoladas, e a natureza do todo é sempre diferente da mera soma de suas partes".

Podemos trazer esses conceitos para a rotina escolar e afirmar que o contexto educacional como um todo e a Sala de Recursos particularmente, como ambiente de interesse para a produção deste trabalho, 
são lugares da multiplicidade, nos quais os participantes dos processos de ensino e aprendizagem desenvolvem múltiplas habilidades e inteligências, como em uma teia, por meio de linguagens várias, interligadas por movimentos circulares que flutuam entre a ordem e o caos, para as quais olharemos com mais detalhe na seção seguinte.

\section{LETRAMENTOS NA TEIA DO TEXTO PRODUZIDO NA ESCOLA INCLUSIVA}

A noção de valorização das diferenças apregoada pela inclusão caminha na direção oposta à concepção inicial de escolarização, que visava a padronizar os alunos e o conhecimento, como descreve Foucault (1977). A escola clássica via a educação como processo homogêneo, ordenava os alunos em uma estrutura de produção e avaliava-os de acordo com uma escala linear de acumulação de saberes, em coerência com a concepção de conhecimento da época.

A inclusão é uma tentativa de conciliar essas impossibilidades causadas pela crise de identidade da modernidade tardia (HALL, 2006) que atinge também a educação (MANTOAN, 2003). Adotamos aqui uma concepção de linguagem como formadora da realidade (FLuSSER, 1963) em alinhamento com a teorização desenvolvida a partir da virada linguística,especialmente com Wittgenstein (VeIGA-Neto, 2007). Desse modo, a realidade é articulada pela linguagem e vista como atividade na interação social, segundo Bronckart ([1999] 2009). Para Lopes (2007), a inclusão é uma invenção produzida na/pela linguagem. É importante notar que "inclusão" é um termo cujo conceito, socialmente construído, vem tendo seu significado em permanente transformação, assim como os demais termos "vivos" da língua, que se alteram conforme o uso, em um processo entrópico de tensão entre os significados já estabelecidos e aqueles que vão surgindo quando utilizados em diferentes contextos, com intenções comunicativas diversas.

Sobre a noção de linguagem como formadora da realidade, Flusser (1963, p. 23) afirma:

Se definimos 'realidade' como 'conjunto dos dados', podemos dizer que vivemos em realidade dupla: na realidade das palavras e na realidade dos dados 'brutos' ou 'imediatos'. Como os dados brutos alcançam o intelecto propriamente dito em forma de palavras, pode- 
mos ainda dizer que a realidade consiste de palavras e de palavras in statu nascendi.

Para esse filósofo, a língua não é referencial, mas um elemento vivo que transforma o caos dos dados imediatos no cosmos das palavras preenchidas de sentido. Cada língua é um cosmos apenas parcialmente compreendido quando traduzido para outra língua ou, outro cosmos, pelas semelhanças e diferenças em sua ontologia.

Em concordância com a possibilidade de compreensão pela tradução, articulada por Flusser (1963), buscamos uma tradutibilidade da linguagem verbal para a não verbal e vice-versa, em meio à busca pela apreensão da realidade operada pela linguagem, em suportes planares visuais. Embora Flusser, Wittgenstein e Bronckart tenham procurado refletir sobre a amplitude do uso linguístico produzido na interação social prioritariamente das línguas ditas naturais, entendemos que algumas de suas conceitualizações podem ser estendidas ao texto visual como um todo.

Mais especificamente, ao nos determos sobre um texto produzido no contexto escolar, nós o concebemos como fruto de uma prática social típica de seu papel na vida dos indivíduos ali presentes, participantes do processo interacional de ensino e aprendizagem no espaço escolar. Também o concebemos como uma teia composta por imagens figurativas bidimensionais que se relacionam às imagens unidimensionais, as palavras verbais.

Consideramos que ocorram, no contexto educacional em que o texto analisado foi produzido, letramentos múltiplos que não se referem apenas ao desenvolvimento da habilidade de ler e escrever com propriedade dentro das regras gramaticais de uma língua natural, mas que envolvem também letramentos em outras linguagens, como a visual e a gestual, em diferentes dispositivos, como a tela do computador e a folha de papel impressa. De acordo com Bagno e Rangel (2005, p. 69), a tarefa de letrar, uma responsabilidade da escola, refere-se a

criar condições para que o indivíduo ou o grupo possa exercer a leitura e a escrita de maneira a se inserir do modo mais pleno e participativo na sociedade tipicamente letrada que é a nossa, especialmente no que diz respeito aos espaços mais institucionalizados do convívio republicano. 
Os ambientes digitais tornam-se espaços cada vez mais importantes para o convívio republicano e os textos verbais, não verbais e sincréticos, produzidos a partir do código binário gerador desses ambientes, invadem a cultura humana na contemporaneidade, tornando urgente o letramento também das linguagens ali utilizadas para fins comunicacionais.

Não é à toa que se fala em letramento digital e que imagens e palavras aparecem cada vez mais juntas, em textos híbridos, facilmente construídos no mundo digital. Já que as ações de letramento visam à inserção na sociedade letrada, podemos inferir que são também ações inclusivas, com o objetivo de formar cidadãos participativos das várias esferas sociais.

Passamos, a seguir, à descrição e análise dos movimentos de circularidade e multiplicidade desenvolvidos por Francisco e sua professora psicopedagoga na Sala de Recursos Multifuncional, em atividade de produção textual como fomento ao(s) letramento(s) na escola inclusiva.

\section{A CIRCULARIDADE ENTRE O VERBAL E O NÃO VERBAL: MOVIMENTOS}

A atividade desenvolvida na Sala de Recursos ocorreu durante três atendimentos individuais do mês de agosto de 2011. A professora psicopedagoga entregou a Francisco seis fichas plastificadas contendo, cada uma delas, um quadrinho da primeira narrativa visual do livro $O$ amigo da bruxinha, de Eva Furnari (1993), intitulada "O telefone".

Francisco deveria pô-las em ordem, de acordo com o que acreditasse que fosse a sequência narrativa. $\mathrm{O}$ aluno fê-lo rapidamente. Em seguida, a psicopedagoga deu-lhe o livro, a fim de que cotejasse sua ordenação das fichas com a sequência narrativa proposta. Seguindo esta ordem, Francisco de imediato descobriu o primeiro quadrinho, delimitado, assim como os demais, por uma faixa retangular de cor lilás que traz o título da história em letras maiúsculas arredondadas, conforme a Figura 1.

Por meio da figura, vemos um sofá, sobre o qual a bruxinha dorme, deitada em posição fetal, sobre um tipo de almofada ou travesseiro com grandes bolas. Ela veste um vestido com bolinhas, usa sapato e chapéu. Enquanto a bruxinha dorme, seu amigo, um gato, a observa 
sentado no mesmo sofá. Ao lado do sofá, pode-se ver um pequeno móvel, sobre o qual estão um telefone e um vaso com uma flor.
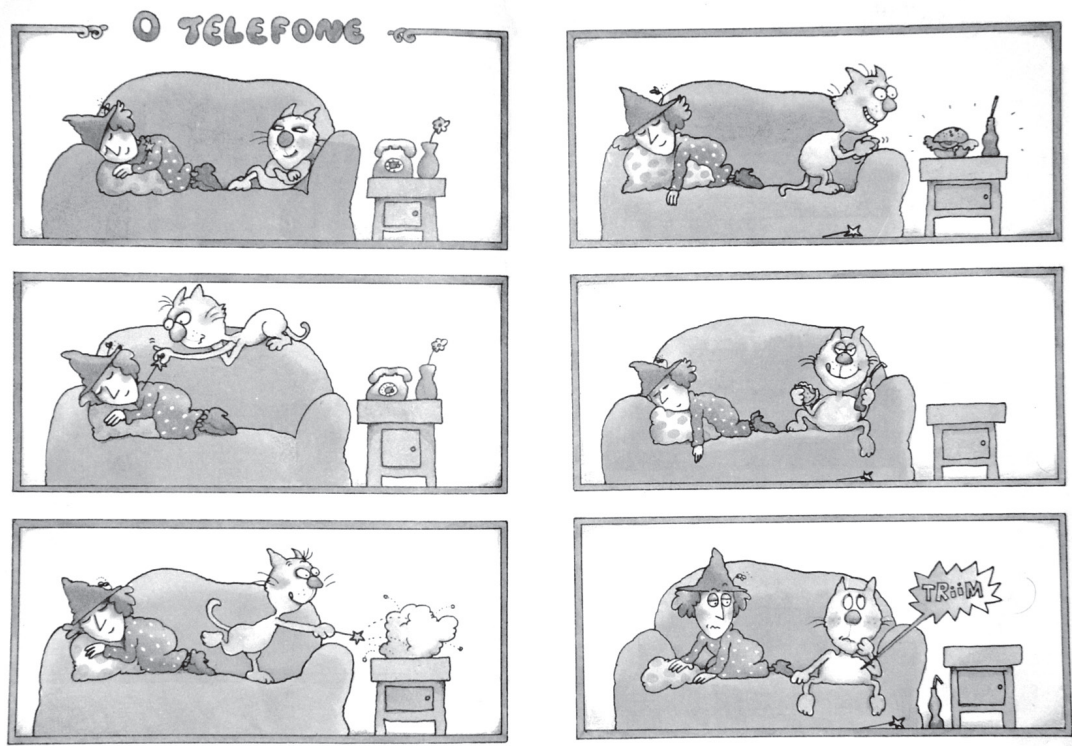

Figura 1. "O telefone”, de Eva Furnari (1993)

No segundo quadrinho, pode-se ver o gato sorrateiramente pegando a varinha mágica entre os braços da bruxinha adormecida. Em seguida, no terceiro quadrinho, o gato empunha a varinha e faz um movimento mágico na direção do telefone e do vaso de flor. No quarto quadrinho, na folha seguinte, os objetos foram transformados, respectivamente, em um hambúrguer e em uma garrafa de refrigerante. $O$ gato os encara com um olhar vidrado, esfregando as mãozinhas, sorridente.

No penúltimo quadrinho, vê-se o gato comendo o hambúrguer e bebendo o refrigerante, sentado de frente, com uma expressão prazerosa. Em todos os quadros até aqui, a bruxinha sempre aparece dormindo, com uma expressão serena. No sexto e último quadrinho, o gato continua sentado de frente, tendo já comido o hambúrguer e bebido quase todo o refrigerante, com um balão de fala saindo de sua barriga, com a expressão 'triim' dentro dele. A bruxinha é retratada acordando, inco- 
modada pelo som do telefone. A varinha mágica e a garrafa de refrigerante quase vazia estão ao chão.

Como podemos ver, a organização plástica da história remete a figuras desenhadas a mão, com traços imprecisos não retilíneos, lembrando o universo infantil. A capa do livro traz a informação de que ele é recomendado para situações de alfabetização. Os quadrinhos trazem um número limitado de informações que se repetem, de modo a tornarem-se facilmente reconhecíveis. Essa repetição de elementos pode auxiliar a desenvolver no aluno uma habilidade referencial e anafórica, estimulando-o a seguir e a compreender a sequência da narrativa.

Depois de organizar as fichas e comparar sua ordenação com a do livro, Francisco foi orientado a utilizar o editor de texto do microcomputador da sala de recursos e escrever essa história com suas próprias palavras. Foi-lhe dada liberdade para renomear a história e referir-se aos personagens e demais elementos conforme seu desejo. A Figura 2 traz a primeira versão da produção textual elaborada por ele no computador e impressa pela psicopedagoga.

\title{
O TELEFONE
}

\begin{abstract}
A BRUXA ALESINHA ESTAVA DOMIDO NOSOFA DA SALA O SEU GATO CHAMADO BEBE ESTAVA DEITADO JUNTO. ENCOTO E ELA ESTAVA DOMIDO OGATO PEGOU A FARINHA MAGICA. COM A VARINHA MAGICA ELE TRAS FOMOU OTELFONEEM CODAIXE E O VAZO DE FLOR EM GARAFINHA DE RIFRI .

E O GATO COMEU O CANDOIXI ETOMOU OREFRI.E ELE FEIS A TRASFOMAÇAO MAUFETA. E O TELIFONE TOGOU DETROR DA BARIGA DO GATO E FOI QUANDO O TELIFONI TOCOU. A BRUXA A CODOU EDEU UM CADIGO PROGATO NÃO DEGUN MAIS DOMI NO SOFA.
\end{abstract}

Figura 2. Versão 1 da produção textual de Francisco

Essa primeira versão do texto verbal de Francisco atesta suas limitações e potencialidades de letramento e traduz as dificuldades geradas pela baixa visão. O garoto opta por manter o título da história de Furnari, mas decide nomear a bruxinha de "Bruxa Alesinha" em virtude de outra personagem bruxa sobre a qual leu em um livro na bibliote- 
ca de sua escola, segundo a psicopedagoga. Apesar de haver alguns registros diferentes aos da convenção ortográfica, de falta de domínio do uso da pontuação e de aspectos relacionados à segmentação de palavras, Francisco demonstra que consegue descrever todos os elementos relevantes da narrativa visual e tem habilidade criativa, pois finalizou a história, provendo-lhe mais uma sequência de acontecimentos, com a Bruxa Alesinha castigando o gato por transformar os objetos em alimentos, não permitindo mais que ele dormisse no sofá.

Nota-se que Francisco, embora já tenha 13 anos de idade, ainda "perde" letras no meio de algumas palavras, deixando de redigi-las, assim como, por vezes, aglutina palavras distintas, como em nosofa, ogato, telfoneem, etomou, orefri, maufeta e progato, revelando incerteza na segmentação das palavras. É interessante observar, porém, que em uma das duas vezes em que redigiu a expressão no sofá, o estudante redigiu as palavras em separado. Acreditamos, portanto, que ele conhece essa separação, mas não é capaz de vê-la e identificá-la sempre.

Especificamente, nota-se que o aluno tem dificuldade em redigir as palavras de acordo com a ortografia quando existem nelas grupos de vogais e consoantes na mesma sequência, como nas palavras dormindo, transformou, transformação, feita e dentro. Esse fato é bastante comum no início do processo de aprendizagem da escrita, quando a criança, nesse caso, pode estar representando os grafemas a partir dos fonemas cuja realização é capaz de perceber.

Naturalmente, consoantes de final de sílaba como "s", "r" e "n" podem passar despercebidas pela criança, já que, na fala, são pronunciadas muito rapidamente, mas, além disso, ela também pode estranhar o fato de haver mais de uma consoante no final da sílaba, optando por uma apenas. Para produções como essas, seria muito pertinente conversar com a criança e fazer-lhe perguntas sobre sua escrita, buscando respostas para compreender suas escolhas. É interessante notar que os registros para os encontros consonantais de início de sílaba foram todos adequados, inclusive nas palavras em destaque, em que a sequência "tr" se evidencia, mas também se encontram ocorrências de "br", em bruxa, por exemplo, e "pr" no registro de progato.

O aluno parece confundir-se com a grafia das consoantes surdas e sonoras, como em farinha/varinha e cadigo/castigo, além de sua escrita mostrar que tem dúvidas quanto ao som e à grafia de consoantes 
como "c" e "s" como em candoixi/sanduíche. Nossa experiência, em pesquisa com dados da escrita infantil, permite dizer que talvez ele ainda não tenha, nesses casos, percebido a diferença quando associa som, distintividade e representação escrita, ou seja, precisa representar, por meio de um grafema, fonemas cujas características são bastante semelhantes, apenas diferenciando-as quanto ao vozeamento: o fonema /f/ é [-vozeado] e o fonema /v/ é [+vozeado], de modo equivalente ao que se verifica em $/ \mathrm{t} / \mathrm{e} / \mathrm{d} /,^{1}$ respectivamente. É importante reforçar que essas ocorrências foram as únicas quanto à diferença de ser vozeado ou não, ou seja, ser produzido com vibração ou não das pregas vocais durante a passagem da corrente de ar pela traqueia. ${ }^{2}$

Mesmo sendo pouco significativa em relação a dados quantitativos, uma conversa com o menino sobre suas escolhas por esses registros poderia ser bastante produtiva. No caso da palavra sanduiche, acreditamos que o grafema "s" tenha sido substituído pelo grafema "c" em razão de, em algum momento, o menino remeter-se à representação do fonema /s/, como em cenoura ou cinema. Assim, parece que ele não se preocupou com a presença da vogal "a", que, após a consoante "c", não possibilita a representação do fonema $/ \mathrm{s} /$, mas do fonema $/ \mathrm{k} /$. Novamente, sugerimos questionar o aluno sobre essa opção de registro. No geral, porém, o texto redigido por Francisco demonstra que ele é capaz de representar graficamente sua intenção de fala e consegue estruturar uma narrativa com início, meio e fim, com título centralizado e frases sinalizadas com ponto final.

No segundo atendimento educacional especial do mês de agosto, foi solicitado a Francisco que revisasse a primeira versão desse seu texto, operação para a qual contou com a ajuda da psicopedagoga. Ela entregou em suas mãos a versão 1 do texto e também a abriu no editor de texto do computador para que o aluno pudesse reescrevê-la. A Figura 3 traz a segunda versão, resultante da reescrita com o auxílio da educadora. A psicopedagoga o alertou sobre a inserção de parágrafos a fim de organizar seu texto e chamou a sua atenção para a ortografia e a separação das palavras que tinham ficado aglutinadas na versão inicial.

Na segunda entrevista, relatou que perguntava ao aluno: como se escreve dormindo? Pronunciava bem devagar dor-min-do e apontava para a palavra digitada, de forma que o aluno logo percebia, pela aten- 
ção ao som em relação às letras, qual letra tinha deixado de escrever. A psicopedagoga afirmou que algumas palavras foram mais difíceis, como sanduíche e garrafinha. Em razão do número elevado de encontros consonantais nessas palavras, ela precisou orientar a redação do aluno de modo mais direcionado.

O TELEFONE
A BRUXA ALESINHA ESTAVA DORMINDO NO SOFÁ
DA SALA O SEU GATO CHAMADO BEBE ESTAVA
DEITADO JUNTO.
ENQUANTO ELA ESTAVA DORMINDO O GATO
PEGOU A VARINHA MÁGICA. COM A VARINHA MÁGICA
ELE TRANSFORMOU O TELEFONE EM SANDUICHE E O
VASO DE FLOR EM GARRAFINHA DE REFRI E O GATO
COMEU O SANDUICHE E TOMOU O REFRI. E ELE FEZ A
TRANSFORMAÇO MAU FEITA.
O TELEFONE TOCOU DENTRO DA BARRIGA DO
GATO. QUANDO O TELEFONE TOCOU A BRUXA
ACORDOU E DEU UM CASTIGO PRO GATO NÃO DEIXOU
MAIS DORMI NO SOFÁ.

Figura 3. Escrita de Francisco com o auxílio da psicopedagoga

No terceiro encontro, a psicopedagoga apresentou a Francisco o software de acessibilidade Comunicar com símbolos que é produzido por uma empresa portuguesa e que foi adquirido para a Sala de Recursos Multifuncional da escola através da verba de acessibilidade. ${ }^{3}$ Com ele, pode-se escrever textos sincréticos que contenham palavras e figuras. Em cima de cada palavra escrita, o programa coloca uma figura que a representa, mostrando ao usuário uma paleta de opções de imagens, em preto e branco ou coloridas, a fim de que ele selecione a mais adequada.

O software é bastante parecido com os editores de texto aos quais estamos acostumados e pode auxiliar em atividades de letramento, porque a imagem somente aparece em cima da palavra quando esta é escrita em sua grafia adequada, além de apresentar ao usuário as variedades de significados possíveis em uma dada palavra, pelas diferentes opções de figuras que ele pode escolher para ilustrá-la. Um exemplo disso ocorre quando digitamos a palavra casa na tela: aparece a opção da imagem de uma casa, com uma porta e uma janela frontal, e a opção de um casal 
de noivos, em vestes cerimoniais, ilustrando o significado de casa e o verbo casar na terceira pessoa do singular do presente do indicativo.

A psicopedagoga entregou a Francisco uma cópia impressa da segunda versão do texto produzido pelo aluno, a reescrita feita com a ajuda dela, e pediu-lhe que digitasse o texto novamente, dessa vez no software Comunicar com símbolos. O aluno não teve dificuldades em cumprir a tarefa, conforme relato da psicopedagoga. Apesar de não mostrar agilidade ao identificar as letras nas teclas, Francisco produziu seu texto com mais facilidade se comparado às tentativas anteriores. A psicopedagoga o deixou livre para alterá-lo, se desejasse, e Francisco modificou algumas palavras na parte final da história, conforme podemos observar nas Figuras 4 e 5.

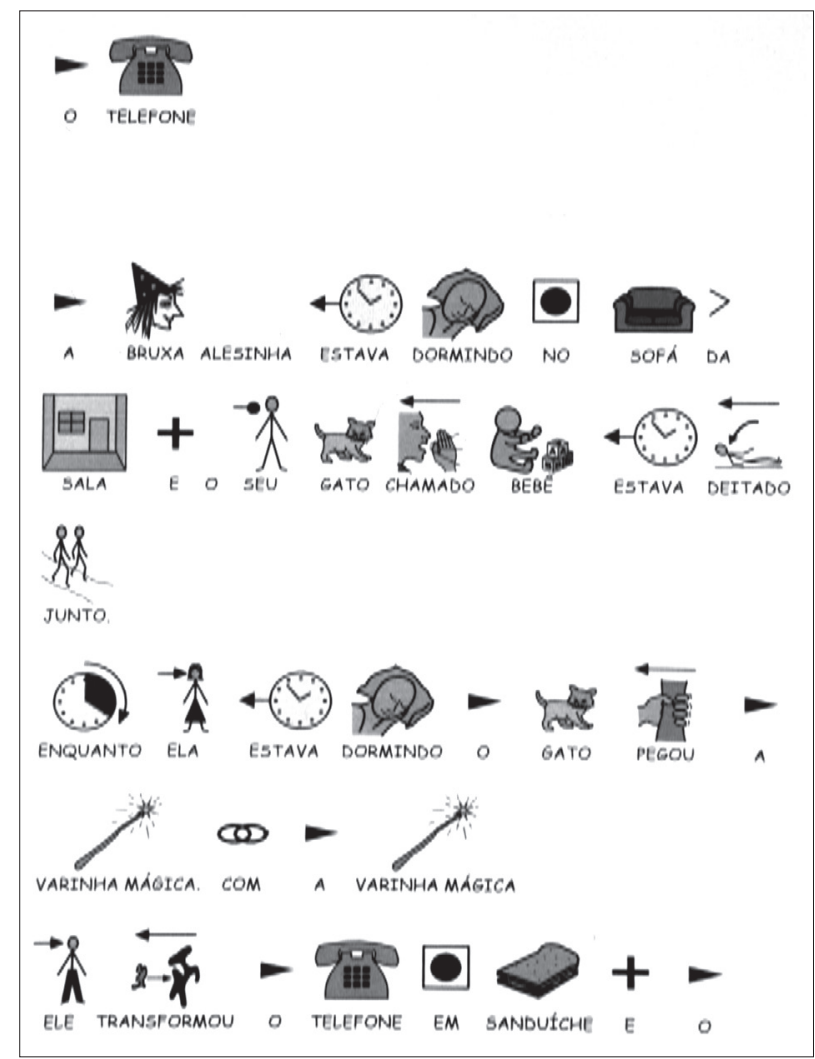

Figura 4. Terceira versão da produção de Francisco 
Dessa vez, o aluno não apresentou dificuldades ortográficas, nem teve problemas na separação das palavras. O software o ajudou a manter as figuras e o léxico empregado, auxiliando-o a perceber a grafia e os elementos dêiticos, anafóricos e catafóricos.

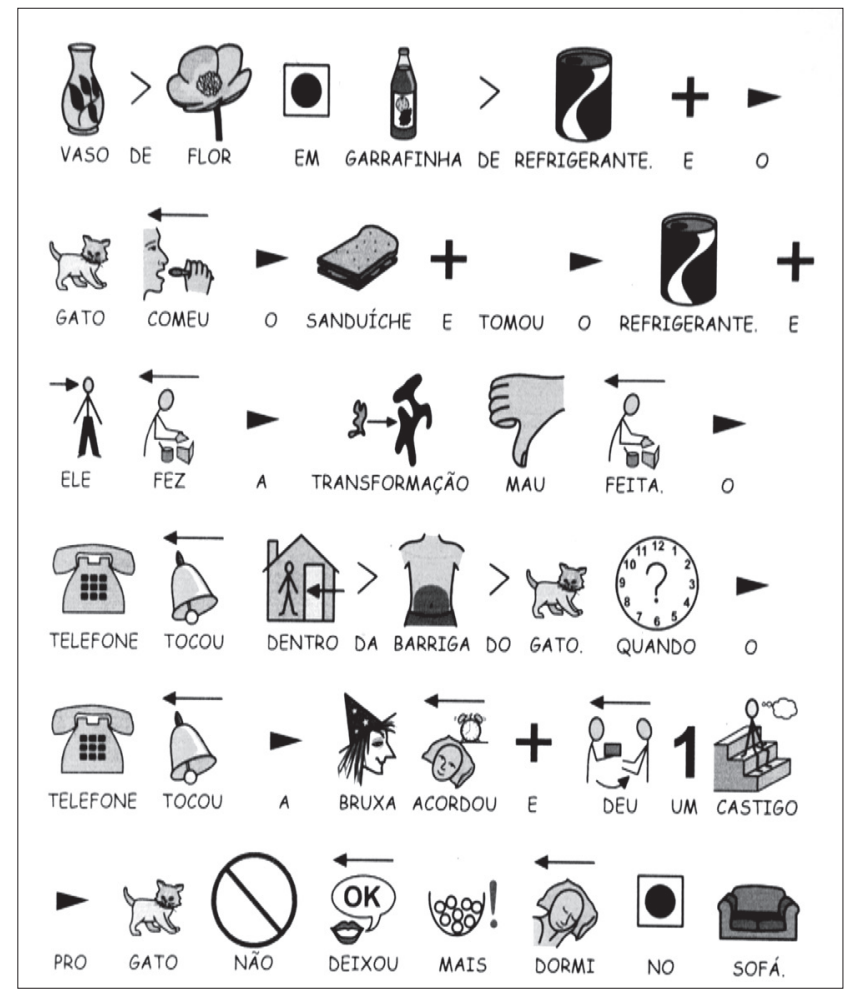

Figura 5. Versão 3, reescrita com o software educativo

\section{Considerações Finais}

Nesse vai e vem de suportes e linguagens, podemos perceber, na produção textual de Francisco, uma série de movimentos de circularidade entre o suporte analógico (papel) e o suporte digital (tela do computador) e entre a linguagem verbal e a não verbal. Partindo da leitura da imagem no papel, no livro de Furnari, Francisco encontrou uma tradutibilidade (FLuSSER, 1963) da narrativa visual do papel para 
a narrativa verbal produzida no editor de texto. O aluno realizou um movimento de reescrita, trabalhando nos dois suportes, tendo no papel a versão 1 e produzindo a versão 2 de seu texto no computador, empregando a linguagem verbal, com o auxílio da psicopedagoga.

Em seu último movimento, Francisco manteve o trabalho com os dois suportes, ancorando-se no analógico e produzindo, na tela do computador, seu texto sincrético ou multimodal, com a ajuda do software de acessibilidade. Nesse último movimento, o aluno trabalhou com dois suportes e duas linguagens conjuntamente, num momento de aprendizagens múltiplas possibilitado pelo código binário do suporte digital. Francisco exercitou-se tanto no sistema semiótico verbal como no não verbal e mostrou progressos de letramento no sentido estrito de letramento linguístico e no sentido amplo de letramentos múltiplos, como o letramento visual e o letramento digital.

No decorrer do ano letivo, foi possível perceber progressos na aprendizagem de Francisco no que concerne às limitações decorrentes de sua baixa visão. $\mathrm{O}$ aluno passou a demonstrar cada vez mais interesse pela leitura, sendo visto com livros frequentemente, nos corredores da escola e até na sala de aula. Isso, às vezes, o atrapalhava até na realização de atividades pontuais nas aulas regulares, pois, em vez de realizar as atividades propostas como os demais colegas, ele queria ler.

Começou lendo histórias em quadrinhos e revistas ilustradas e passou para textos mais extensos no decorrer do ano letivo. No conselho de classe final, a professora de português relatou que o aluno ainda apresentava dificuldades para copiar do quadro, mas já conseguia separar a maioria das palavras, indagando-o sobre aquelas a respeito das quais tinha dúvidas.

A psicopedagoga continuou dando ênfase ao letramento durante os atendimentos de Francisco, buscando atingir o máximo possível dos objetivos propostos em seu plano de estudos para o Atendimento Educacional Especializado, intercalando as sessões com foco na produção textual com atividades enfatizando a compreensão, interpretação e resolução de histórias matemáticas.

Francisco foi aprovado ao final do ano letivo e segue frequentando a escola regular, a Sala de Recursos Multifuncional e os demais atendimentos proporcionados pela Rede de Saúde e Educação públicas. Atualmente, está em fila de espera do SUS para a realização de cirurgia 
que deve abrandar as suas limitações motoras. $\mathrm{O}$ aluno tem demonstrado aprofundamento e evolução em atividades que envolvem letramentos, embora a chegada da adolescência tenha alterado bastante o foco da atenção dele para questões de cunho social e de seu grupo de amigos, como é comum em sua faixa etária.

Precisamos investir nos recursos disponíveis e acessíveis a alunos e professores, pois, mesmo diante das especificidades de Francisco, a reflexão aqui desenvolvida revelou suas potencialidades e seu aproveitamento produtivo daquilo que lhe foi oferecido. Trouxemos aqui alguns movimentos dos professores, da comunidade escolar e de Francisco e ressaltamos que outros movimentos e outros agentes devem se manifestar na realidade escolar, visando ao ensino e à aprendizagem de línguas.

Os movimentos circulares desempenhados pelo aluno, em sua atividade de produção textual, na Sala de Recursos, evidenciam que as atividades inclusivas dentro da escola podem exemplificar a potencialidade da visão sistêmica sobre a educação, os letramentos e as linguagens enquanto sistemas abertos em mudança permanente. Nesse sentido, vale destacar a afirmação de Luz (2006, p. 42): “A escola é puro movimento".

THE CIRCULARITY AMONG SEMIOTIC SYSTEMS AS A SUPPORT TO LITERACY(IES) AT THE INCLUSIVE SCHOOL

\section{ABSTRACT}

The notions of multiplicity and circularity from the systems theory structure this paper, in which a text produced in an activity applied in the Multifunctional Pedagogical Support Room was analyzed and the linguistic development of an inclusion student was debated. The option for the multiplicity and circularity present in the student's process of writing and the notion of inclusion, literacy(s) and semiotic systems are based on the conception of language as action. The circular movements performed by the student in his writing activity reiterate the potential in systemic view about languagesand literacy(s) as open systems in continuous change.

KeY WORDS: semiotic systems, literacies, inclusive school, multifunctional pedagogical support room. 


\section{NOTAS}

1 Na palavra castigo, considerando a variante falada na região, tem-se, de um modo geral, a pronúncia cas[ts]igo para o grafema "t" e, para o grafema "d", cas[d3]igo.

2 Para mais informações sobre aspectos articulatórios na produção das consoantes, sugerimos a leitura de Silva (2002).

3 Verba do Ministério da Educação designada às escolas públicas para a compra de equipamentos e materiais pedagógicos com finalidades inclusivas.

\section{REFERÊNCIAS}

Bagno, Marcos; Rangel, Egon. Tarefas da educação linguística no Brasil. Revista Brasileira de Linguística Aplicada, v. 5, n. 1, p. 63-82, 2005.

Brasil, Ministério da Educação. Diretrizes nacionais para a educação especial na educação básica. Secretaria de Educação Especial: MEC; SEESP, 2001.

Bronckart, Jean-Paul. Atividade de linguagem, textos e discursos: por um interacionismo sociodiscursivo. Tradução de Anna Rachel Machado. São Paulo: EDUC. [1999]2009.

Calvino, Ítalo. Seis propostas para o próximo milênio. Tradução de Ivo Barroso. São Paulo: Companhia das Letras, 1990.

CAPRA, Fritjof. A teia da vida: uma nova compreensão cientifica dos sistemas vivos. Tradução de Newton Roberval Eichemberg. São Paulo: Cultrix, 1996.

CARVALHo, Rosita Edler. Removendo barreiras para a aprendizagem: educação inclusiva. Porto Alegre: Mediação, 2000.

Foucault, Michel. Vigiar e punir. Petrópolis: Vozes, 1977.

Flusser, Vilém. Língua e realidade. São Paulo: Editora Herder, 1963.

Furnari, Eva. O amigo da bruxinha. São Paulo: Moderna, 1993.

GARDNER, Howard. Inteligências múltiplas: a teoria na prática. Tradução de Maria Adriana Veríssimo Veronese. Porto Alegre: Artes Médicas, 1995.

Hall, Stuart. A identidade cultural na pós-modernidade. Tradução de Tomaz Tadeu da Silva e Guacira Lopes Louro. Rio de Janeiro: DP\&A, 2006.

LoPEs, Maura Corcini. Inclusão escolar, currículo, diferença e identidade. In: .; DaL'Lgna, Maria Cláudia (Org.). In/exclusão: nas tramas da escola.

Canoas: Ed. ULBRA, 2007. 
Luz, Arisa Araújo da. Uma educação que é legal! É possivel a inclusão de todos na escola? Tese (Doutorado) - Programa de Pós-graduação em Educação, Universidade do Vale do Rio dos Sinos, São Leopoldo, 2006.

Mantonn, Maria Teresa Eglér. Inclusão escolar: o que é? Por quê? Como fazer? São Paulo: Moderna, 2003.

SiLva, Thais Cristofaro. Fonética e fonologia do português: roteiro de estudos e guia de exercícios. São Paulo: Contexto, [1996]2002.

Veiga-Neto, Alfredo; Lopes, Maura Corcini. Identidade, cultura e semelhança de família: as contribuições da virada linguística. In: Bizarro, Rosa (Org.). $O$ eи e o outro. Porto: Areal, p. 19-35. 2007. 